\title{
Prace Paula Otleta a World Wide Web ${ }^{1}$
}

\begin{abstract}
Streszczenie. W projektach Paula Otleta daje się wskazać podobieństwa do systemu hipertekstowego World Wide Web. Badacze wywodzący się z różnych środowisk (m.in. medioznawczych, socjologicznych, informatycznych, bibliologiczno-informatologicznych) zwracają uwagę na podobieństwa pomiędzy projektami systemu informacyjno-wyszukiwawczego Otleta a WWW. Celem artykułu jest próba odpowiedzi na pytania, czy projekty Otleta są zbieżne pod pewnymi względami z WWW oraz czy tworząc Web, wzorowano się na pracach Otleta.
\end{abstract}

SŁowA KLuczowe: World Wide Web, Paul Otlet.

\section{Wprowadzenie}

Prace Paula Otleta wniosły wiele przede wszystkim do bibliologii i informatologii². Można w nich odnaleźć również pomysły, które zrealizowano dopiero w środowisku hipertekstowym World Wide Web. „Oto

1 Zasadnicza część prezentowanego tekstu pochodzi z obronionej 20 marca 2013 roku na Wydziale Historycznym Uniwersytetu Warszawskiego rozprawy doktorskiej zatytułowanej Komunikacja bibliologiczna wobec World Wide Web, napisanej pod kierunkiem prof. dr hab. Jadwigi Woźniak-Kasperek.

2 Por. K. Migoń, Bibliologia - nauka o kulturze książi, „Nauka” 2005, nr 2, s. 52-53; W. Boyd Rayward, The case of Paul Otlet, pioneer of information science, internationalist, visionary: reflection on bibliography, "Journal of Librarianship and Information Science" 1991, t. 23, nr 3, s. 135-145; B. Sosińska-Kalata, Dziedzictwo Paula Otleta i wspótczesna nauka o informacji, w: Książka zawsze obecna. Prace ofiarowane profesorowi Krzysztofowi Migoniowi, red. M. Skalska-Zlat, Wrocław 2010, s. 85-105; E. Żgutowicz, Bibliologiczna koncepcja nauki o informacji Paula Otleta, "Studia o Książce” 1977, t. 7, s. 129-137. Krzysztof Migoń przedstawił szczegółowo koncepcję bibliologii Otleta, tj. wielkiej, uniwersalnej nauki, której obiektem badań są różnego rodzaju dokumenty i ich funkcjonowanie - por. K. Migoń, Paul Otlet o bibliologii, książce i dokumencie, "Zeszyty Naukowe Uniwersytetu Jagiellońskiego. Prace z Bibliotekoznawstwa i Informacji Naukowej" 2004, z. 10, s. 70-77. 
bowiem w różnego rodzaju opracowaniach naukowych i popularnonaukowych dotyczących hipertekstu - komputerowego systemu organizacji danych tekstowych Otlet pojawia się w roli «koncepcyjnego ojca»" ${ }^{3}$. Reprezentanci między innymi bibliologii i informatologii ${ }^{4}$, historii nauki ${ }^{5}$, informatyki ${ }^{6}$, literaturoznawstwa ${ }^{7}$, medioznawstwa ${ }^{8}$, komunikologii $^{9}$, naukoznawstwa ${ }^{10}$ czy socjologii ${ }^{11}$ uznają Otleta za twórcę koncepcji hipertekstu i hiperłącza ${ }^{12}$. Celem artykułu jest próba odpowiedzi na pytania, czy projekty Otleta są zbieżne pod pewnymi względami z WWW oraz czy tworząc Web, wzorowano się na pracach Otleta.

Informatycy oraz komunikolodzy twierdza, że Otlet w 1934 roku $\mathrm{w}$ rozprawie Traité de documentation przedstawił zalążki hipertekstu. Również wielu publicystów uważa, że w pracach Otleta można odnaleźć pierwowzór hiperłącza ${ }^{13}$. Dodają oni, że Otlet stworzył projekt ogólnoświatowej sieci komputerowej, która miała umożliwiać użytkownikom

3 M. Góralska, Bibliologia wobec informatyzacji systemu komunikacji społecznej. Wybrane zagadnienia, "Zagadnienia Informacji Naukowej” 2005, nr 2, s. 46.

4 Por. R. Day, Paul Otlet's book and the writing of social space, w: Historical studies in information science, red. T.B. Hahn, M. Buckland, Medford 1998, s. 43-50.

5 The Britannica guide to inventions that changed the modern world, red. R. Curley, New York 2010, s. 100.

6 Por. Y. Marchland, J.L. Guérin, J.P. Barthès, From a set of technical documents to a hypertext system on the Web, „Webnet” 1996 [online], [dostęp: 19.03.2012], dostępny w internecie:http://algo.informatik.uni-freiburg.de/bibliothek/proceedings/webnet96/ Html/203.htm; J.M. Reagle Jr., Good faith collaboration: the culture of Wikipedia, Cambridge 2010, s. 23.

7 Por. A. Codrescu, The posthuman Dada guide: Tzara E Lenin play chess, Princeton 2009, s. 164.

8 Por. P. Krapp, Noise channel: glitch and error in digital culture, Minneapolis 2011, s. 14.

9 Por. P.B. Seel, Digital universe: the global telecommunication revolution, Malden 2012, s. 91.

10 S. Restivo, Science, technology, and society, Oxford 2005, s. 220.

11 Por. A. Miller, Cultural barriers to organization social media adoption, w: Social knowledge: using social media to know what you know, red. J.P. Girard, J.L. Girard, Hershey 2011, s. 96-96.

12 Por. A. Møller, M.I. Schwartzbach, An introduction to XML and Web technologies, Glasgow 2006, s. 3; J.M. Noyer, A. Serres, De Paul Otlet a Internet en passant par hypertexte [online], [dostęp: 24.01.2008], dostępny w internecie: http://www.uhb.fr/urfist/ SerreDEF.htm.

13 Por. E. Hanes, Dec. 10, 1944: Web visionary passes into obscurity [online], [dostęp: 11.03.2012], dostępny w internecie: http://www.wired.com/thisdayintech/tag/paulotlet/. 
korzystanie z bazy różnych typów dokumentów połączonych hiperłączami. Przyjmują zatem, że antycypował on hipertekstualną strukturę dzisiejszego $\mathrm{Webu}^{14}$.

Pod koniec XIX wieku Otlet opublikował artykuł, w którym stwierdził,

że o wiele bardziej niż opis formalny publikacji istotny jest opis jej treści i zawartych w niej wniosków. [...] w związku z tym zasugerował analizowanie piśmiennictwa według czterech głównych kategorii: fakty, ich interpretacja, statystyki i źródła; taka analiza powinna odzwierciedlać charakter publikacji i wskazywać jej wkład do wiedzy na określony temat. Informacje te, uzupełnione odpowiednio przygotowanym streszczeniem, powinno się - jego zdaniem - gromadzić na kartach dokumentacyjnych, zestawionych na kształt encyklopedii lub katalogu przedmiotowego i powiązanych ze sobą przejrzystym systemem odsyłaczy ${ }^{15}$.

Realizacja tej koncepcji wymagała zastosowania odpowiedniego nośnika, na którym można by rejestrować poszczególne jednostki bibliograficzne. Początkowo Otlet zainteresowany był wykorzystaniem fotografii mikrofilmowej. Papier jako nośnik był bowiem pod względem fizycznym za ciężki i zajmował zbyt dużo przestrzeni. Dokumenty mikrofilmowe zdawały się o wiele dogodniejsze, między innymi dlatego, że łatwiej i taniej można je było powielać, transportować i rozpowszechniać. W 1906 roku wraz z Robertem Goldschmidtem Otlet zaproponował, aby wykorzystać nowy nośnik i format zarazem, tj. mikrofiszę, która zapewniała znaczną oszczędność miejsca. Jednakże powody techniczne, czyli brak odpowiedniego sprzętu do kopiowania informacji z kartek, jak również brak dobrych urządzeń do odczytu informacji z mikroform spowodowały, że zdecydował się ostatecznie wykorzystać papier ${ }^{16}$. „Otlet

${ }^{14}$ Por. M. Laaff, Internet visionary Paul Otlet: networked knowledge, decades before Google [online], [dostęp: 12.03.2012], dostępny w internecie: http://www.spiegel.de/ international/world/0,1518,775951,00.html; A. Wright, Forgotten forefather: Paul Otlet [online], [dostęp: 19.03.2012], dostępny w internecie: http://www.boxesandarrows. com/view/forgotten_forefather_paul_otlet; idem, The Web time forgot, "New York Times", 17.06.2008 [online], [dostęp: 2.08.2011], dostępny w internecie: http://www. nytimes.com/2008/06/17/science/17mund.html?_r=2\&.

15 A. Augustyniak, Dokumentacja naukowa - powstanie i rozwój do 1914 roku, w: Informacja naukowa. Rozwój-metody - organizacja, red. Z. Żmigrodzki, W. Babik, D. Pietruch-Reizes, Warszawa 2006, s. 45-46.

${ }^{16}$ M.K. Buckland, Emanuel Goldberg and his knowledge machine: information, invention, and political forces, Westport 2006, s. 63. 
projektował i wdrażał «technologię informacyjną» swoich czasów, opartą na dokumentacyjnych kartotekach kartkowych i nowej wówczas technice mikrofotografii" ${ }^{\prime 17}$.

\section{Podobieństwa do systemów hipertekstowych}

Otlet na przestrzeni lat w licznych pracach przedstawiał zasadę (ang. monographic principle), według której tekst znajdujący się w książce czy artykule powinien zostać „rozbity” na mniejsze, określone znaczeniowo części. Następnie każda z tych części powinna zostać oddzielnie zarejestrowana i opisana treściowo. Części te miały być łączone odsyłaczami ${ }^{18}$. Wynikiem tak prowadzonej pracy byłaby informacja w "kawałkach”, "porcjach”, którą dalej można by zestawiać w pożądanych układach.

Otlet widział konieczność wydobywania [...] informacji z książek [...], tworzenia z nich znormalizowanych komunikatów, a następnie utrwalania ich na osobnych nośnikach tworzących kolekcje, które pod względem funkcjonalności przypominałyby dzisiejsze bazy danych. $W$ ramach takich zbiorów informacje mogłyby podlegać dalszemu podziałowi lub porządkowaniu sieci wzajemnych tematycznych powiązań ${ }^{19}$.

Stąd na stronie internetowej Międzynarodowej Unii Intelektualnej (Union of International Associations), założonej w 1907 roku przez Henriego La Fontaine'a i Otleta, można przeczytać, że wizja sieci wiedzy Otleta oparta była na pomyśle zgromadzenia różnych dokumentów i powiązania ich za pomocą hiperłączy („his vision of a network of knowledge was based on documents and included notions of hyperlinks" $)^{20}$. Dyrektor ds. komunikacji i badań naukowych Międzynarodowej Unii Intelektualnej Anthony Judge wyjaśnił, że trójczłonowa nazwa unii również odzwierciedlała założenia Otleta. Słowo union miało sugerować tworzenie zespołu organizacji, które $\mathrm{w}$ ramach ujednoliconych przepisów, norm i standardów będą prowadzić scentralizowane i skoordynowane

${ }^{17}$ B. Sosińska-Kalata, Dziedzictwo Paula Otleta..., s. 97.

${ }^{18}$ Por. S. Sonvilla-Weiss, (In)visible learning to act in the metaverse, Wien 2008, s. 19.

19 M. Góralska, op.cit., s. 46.

${ }^{20}$ Por. Paul Otlet (1868-1944) [online], [dostęp: 12.03.2012], dostępny w internecie: http://www.uia.be/paul-otlet-1868-1944. Nazwy „Międzynarodowa Unia Intelektualna" używa Anna Augustyniak jako tłumaczenia The Union of International Associations. Por. A. Augustyniak, Dokumentacja naukowa..., s. 44-57. 
działania, słowo international - że działania te będą miały zasięg międzynarodowy, wreszcie słowo associations - że w ramach tej współpracy powstanie swoista sieć osób i instytucji zaangażowanych w prace w ramach unii $^{21}$. W Wikipedii można przeczytać, że

ideą Otleta było utworzenie systemu gromadzenia wiedzy i udostępniania jej jak największej liczbie ludzi. Chociaż żył i pracował w erze przed zaistnieniem sieci komputerowych, antycypował wiele późniejszych idei i przyczynił się do rozwoju pomysłów, które doprowadziły po dziesięcioleciach do powstania WWW. Jedną z jego wizji była wiedza zatomizowana w postaci precyzyjnie sklasyfikowanych pojęć, powiązanych ze sobą za pomocą hiperłączy ${ }^{22}$.

Jak widać, Otlet zaproponował, aby łączyć obiekty $w$ sieci relacji. W zasadzie tworzenia nielinearnych powiązań asocjacyjnych można doszukiwać się idei hipertekstu, później przedstawionej zwłaszcza przez Vannevara Busha.

Karty katalogowe zawierające dane pochodzące $\mathrm{z}$ różnych źródeł można byłoby grupować zgodnie z zapytaniem. W rezultacie poszukujący uzyskiwałby wszystkie znajdujące się w systemie informacje na dany temat. Karty katalogowe umożliwiały rejestrowanie „określonych porcji” informacji (treści), zarówno pod względem formalnym, jak i pod względem rzeczowym, a więc de facto były podobne do tego, co określa się mianem „węzłów" i „leksji” w dzisiejszym hipertekstowym środowisku $\mathrm{WWW}^{23}$.

Opis formalny „porcji informacji” wskazuje „miejsce”, z którego pochodzi zarejestrowana informacja. Jest to zbieżne z adresem URL stworzonym na potrzeby hipertekstowego Webu. Opis rzeczowy „porcji informacji" przynosi jej treść, co z kolei nasuwa skojarzenia z funkcjonującymi w WWW leksjami, tj. najmniejszymi znaczeniowo fragmentami hipertekstu. W obydwu przypadkach użytkownik uzyskuje informację na temat danego obiektu informacyjnego, jak również treść tego obiektu.

${ }^{21}$ Por. A. Judge, Paul Otlet's 100-year hypertext conundrum? Union of International Associations - virtual organization, "Transnational Associations” 2003, nr 1-2, s. 107-111. Dostępny również w internecie: http://www.laetusinpraesens.org/docs/otlethyp.php [dostęp: 24.03.2012]. Por. także H. Jarecka, La Fontaine i Paul Otlet jako pionierzy międzynarodowej wspótpracy intelektualnej, „Aktualne Problemy Informacji i Dokumentacji" 1986, t. 31, nr 5, s. 3-6.

22 Paul Otlet, w: Wikipedia. Wolna encyklopedia [online], [dostęp: 19.11.2010], dostępny w internecie: http://pl.wikipedia.org/wiki/Paul_Otlet.

23 Por. W. Boyd Rayward, Visions of Xanadu: Paul Otlet (1868-1944) and hypertext, „Journal of the American Society for Information Science” 1994, t. 45, nr 4, s. 237. 
Na potrzeby stworzonego niemalże 100 lat później Webu wykorzystano już potencjał komputerów i sieci internetowej, których w czasach Otleta jeszcze nie było ${ }^{24}$.

W rozbiciu tekstu dokumentu na mniejsze całości dostrzega się podobieństwo do systemu hipertekstowego, w którym teksty również są (mogą być) rozbite na mniejsze całości (leksje). Kolejnym podobieństwem jest to, że we współczesnym systemie hipertekstowym można bez problemu trafić do źródła leksji, a z kolei w projekcie Otleta użytkownik mógł dotrzeć do dokumentu pierwotnego przez opis bibliograficzny ${ }^{25}$. Tworzona w ten sposób baza miała być uporządkowana za pomocą Uniwersalnej Klasyfikacji Dziesiętnej (UKD) ${ }^{26}$. Otlet proponował zatem, aby tradycyjna, tj. skupioną na opisie książek, bibliografię zastąpić nową formą działalności, która miała zająć się wyodrębnianiem szczegółowych treści zawartych $\mathrm{w}$ różnych dokumentach oraz rejestrowaniem ich $\mathrm{w}$ łatwych do przeszukiwania kartotekach, które miały być uporządkowane zgodnie z UKD ${ }^{27}$. Barbara Sosińska-Kalata zwróciła uwagę na fakt, iż pod koniec XIX wieku nastąpił znaczny przyrost informacji, z których wiele szybko się dezaktualizowało. Poza tym były one rozproszone $\mathrm{w}$ dokumentach, co utrudniało ich odnajdywanie. Stąd jednym z priorytetów działalności Otleta i La Fontaine'a stało się zbudowanie nowoczesnej uniwersalnej klasyfikacji dokumentacyjnej ${ }^{28}$.

Zdaniem profesora historii i mechaniki na Uniwersytecie w Houston Johna H. Lienharda historia „wynalazku” hiperłącza sięga XIX wieku, kiedy nastąpił znaczy wzrost produkcji wydawniczej (drukowanie tanich książek ${ }^{29}$. W związku z funkcjonowaniem na rynku coraz większej liczby książek coraz trudniejsze stawało się odszukiwanie $w$ nich potrzebnych

${ }^{24}$ Por. ibidem, s. 245. Otlet „,antycypował powstanie takich urządzeń, jak współczesne komputery osobiste, podłączone do sieci telekomunikacyjnych i wyposażone w specjalistyczne oprogramowanie do przetwarzania tekstów, grafiki, dźwięku, mowy". B. Sosińska-Kalata, Dziedzictwo Paula Otleta..., s. 102.

25 Pomysły dotyczące usprawnienia klasyfikowania zbiorów bibliotecznych zrealizował, współtworząc Uniwersalną Klasyfikację Dziesiętną. Por. B. Sosińska-Kalata, Podręcznik UKD dla bibliotekarzy i pracowników informacji, Warszawa 1995, s. 67.

${ }^{26}$ Por. S. Sonvilla-Weiss, op.cit., s. 19; A. Augustyniak, Dokumentacja naukowa..., s. 46. UKD bywa nazywana „szczytowym osiągnięciem myśli klasyfikacyjnej”. Por. Bibliotekarstwo, red. Z. Żmigrodzki, J. Ratajewski, A. Tokarska, Warszawa 1994, s. 127.

27 Por. B. Sosińska-Kalata, Dziedzictwo Paula Otleta..., s. 95.

${ }^{28}$ Por. B. Sosińska-Kalata, Klasyfikacja: struktury organizacji wiedzy, piśmiennictwa i zasobów informacyjnych, Warszawa 2002, s. 153-154.

${ }^{29}$ J.H. Liendhard, Inventing the hyperlink [online], [dostęp: 8.03.2012], dostępny w internecie: http://www.uh.edu/engines/epi2388.htm. 
informacji. Rozwiązaniu, choćby częściowemu, tego problemu miały służyć klasyfikacje dokumentacyjne, w tym klasyfikacja dziesiętna Melvila Deweya - KDD (1876). Niespełna 20 lat później Otlet, korzystając z tej klasyfikacji, zauważył, że poważnym jej brakiem było to, że w rezultacie kwerendy użytkownik prowadzony był tylko do jednego, konkretnego źródła lub do zbioru źródeł ${ }^{30}$.

Po dokonaniu oceny różnych systemów klasyfikacji, takich jak system dziesiętny Melvila Deweya czy system stosowany w British Museum, Otlet doszedł do wniosku, że posiadają one jedną zasadniczą wadę - są projektowane tak, aby użytkownika doprowadzić tylko i wyłącznie do jednej książki. Wizjoner [Otlet S.D.K.] zapragnął, aby jego system nie tylko opisywał treść dokumentów, ale również aby gromadził informacje na temat przestrzeni, w jakiej funkcjonuje każdy dokument ${ }^{31}$.

Stwierdzenia o docieraniu przez KDD do jednego dokumentu należy rozumieć tak, że użytkownik prowadzony był linearnie. Klasyfikacje odsyłają do wielu dokumentów, jednak droga, którą przebywa użytkownik, jest liniowa. Tymczasem UKD zdawała się pod tym względem bardziej elastyczna, ponieważ pozwalała przemieszczać się zarówno linearnie po szczeblach klasyfikacji, jak i nielinearnie pomiędzy dokumentami i omijać niejako szczeble klasyfikacji. Dzięki temu użytkownik mógł nie tylko odnaleźć konkretne dokumenty, ale również dotrzeć do innych powiązanych z tymi, które odnalazł. Powstawała w ten sposób sieć powiązanych ze sobą za pomocą UKD źródeł. W tej strukturze można doszukiwać się podobieństwa do struktury hipertekstu.

Chcąc znaleźć kolejne dokumenty, należało ponownie przeprowadzić wyszukiwanie. W związku z tym Otlet rozpoczął prace nad nowym sposobem porządkowania wiedzy. Zaproponował standard karty katalogowej (fiszki) i własną klasyfikację, opartą na klasyfikacji Deweya ${ }^{32}$. Wzbogacona ona została $\mathrm{w}$ możliwość tworzenia połączeń pomiędzy dokumentami na podobny temat (ang. cross-linking subject). Dla przykładu książka poświęcona zagadnieniu „siarka w stali” zostaje opisana symbolami „siarka” i „stal” połączonymi dwukropkiem. W ten sposób

${ }^{30}$ Ibidem.

${ }^{31}$ H. Zarębska, Śmiałe pomysty Paula Otleta - belgijskiego naukowca, twórcy informacji naukowej, „Nowa Biblioteka” 2010, nr 2, s. 88.

32 O przyczynach wykorzystania przez Otleta i La Fontaine'a KDD zob. A. Augustyniak, Międzynarodowa Federacja Informacji i Dokumentacji, "Przegląd Biblioteczny” 2004 , z. $1 / 2$, s. 6. 
powstaje jednocześnie odwołanie (odesłanie) do kolejnej książki, tj. rodzaj hiperłącza. Znajdując publikacje na temat „stali”, odnaleźć można także odwołanie do książek na temat „,siarki”. W rezultacie po znalezieniu pracy na temat „stali" można dotrzeć do książki na temat „siarki w stali”33.

Od początku istnienia UKD klasyfikacja ta dysponowała rozbudowanym systemem podziałów wspólnych i analitycznych [...]. W UKD stosuje się specjalne znaki (m.in. znak plus, kreskę ukośną i dwukropek) służące do syntezy symboli głównych lub pomocniczych. W KDD brak takich znaków, a synteza jest często realizowana przez bezpośrednie dołączenie danych symboli głównych lub ich elementów do innego symbolu głównego. Struktura UKD cechuje się zatem większą fasetowością niż struktura KDD. UKD charakteryzuje się też większą zdolnością odwzorowywania złożonej treści dokumentów niż KDD ${ }^{34}$.

Guy Teasdale, wykładowca uniwersytecki specjalizujący się w systemach bibliotecznych, informacje zawarte na fiszkach uznaje za odpowiedniki hipertekstowych węzłów, pomiędzy którymi powiązania (hiperłącza) umożliwiało zastosowanie UKD ${ }^{35}$. UKD zapewnia "nie tylko precyzyjne wyrażanie zawartości tematycznej dokumentów, ale również wszechstronne ukazanie relacji między nimi"36.

W 1910 roku Otlet wraz z La Fontaine'em rozpoczęli projekt stworzenia uniwersalnego katalogu światowej wiedzy ${ }^{37}$. Propozycja Otleta była de facto próbą stworzenia światowej sieci dokumentacyjnej oraz międzynarodowego centrum wiedzy ${ }^{38}$. Tłumacz dzieł Otleta na język angielski W. Boyd Rayward wyjaśniał, że pisał on w swoich pracach o koncepcji powszechnego katalogu, który obejmowałby nauki społeczne. Tworzenie katalogu w postaci oddzielnych kart pozwalałoby na swobodne manipulowanie nimi w zakresie wyznaczanym możliwościami zastosowanej w katalogu klasyfikacji, umożliwiałoby również tworzenie nowych zestawień (elementy łączone byłyby w określone relacje - zgodnie z kwerendą). Przy okazji zastosowane porządkowanie materiału i otwarta

${ }^{33}$ Por. J.H. Liendhard, op.cit.

${ }^{34}$ E. Ścibor, KDD a UKD: przeszłość, stan obecny, perspektywy, „Przegląd Biblioteczny" 1994, z. 3/4, s. 256-257.

35 Por. G. Teasdale, L'hypertexte: historique at applications en bibliothéconomie, „Cursus" 1995, t. 1, nr 1 [online], [dostęp: 19.03.2012], dostępny w internecie: http://www. ebsi.umontreal.ca/cursus/vol1no1/teasdale.html.

${ }^{36}$ H. Zarębska, op.cit., s. 88.

37 Por. S. Sonvilla-Weiss, op.cit., s. 20.

${ }^{38}$ Por. B. Sosińska-Kalata, Dziedzictwo Paula Otleta..., s. 89. 
struktura dawałyby sposobność nieograniczonego rozrastania się katalogu. Zamierzeniem Otleta było, aby każde z państw tworzyło tego typu katalog narodowy. Zachowanie tej samej struktury umożliwiłoby z czasem połączenie wszystkich narodowych katalogów i stworzenie jednego katalogu uniwersalnego ${ }^{39}$. Chęć objęcia tym katalogiem pełnego uniwersum dokumentów sprawiła, że oprócz dokumentów bibliograficznych, graficznych, ikonograficznych uwzględnione miały być także tzw. dokumenty zastępcze, substytuty książki (substiuts du livre: płyty fonograficzne, fonogramy, inskrypcje, instrumenty naukowe, materiał dydaktyczny, medale, monety, pieczęcie, filmy, nagrania radiowe, telefotografia, nagrania telewizyjne itp. $)^{40}$. Powołany jeszcze pod koniec XIX wieku, m.in. z inicjatywy Otleta, Międzynarodowy Instytut Bibliograficzny miał realizować przedsięwzięcie stworzenia uniwersalnej biblioteki, bibliografii powszechnej oraz opierającej się na nich informacji o piśmiennictwie ${ }^{41}$.

Zamierzeniem Otleta było zapewnienie wglądu w treść całej produkcji piśmienniczej, przedstawionej w sposób syntetyczny i uporządkowanej zgodnie ze szczegółowym podziałem wiedzy, łatwo aktualizowanej i przeszukiwalnej dzięki kartotekowej formie zapisu. Wiedza zawarta we wszelkich dokumentach miała być rekonstruowana na kartach (arkuszach) przygotowywanej kartoteki. Otlet chciał więc stworzyć „uniwersalną księgę", tj. skondensować wiedzę w ograniczonej liczbie dzieł i całą tak zindeksować, aby łatwo można było z niej korzystać ${ }^{42}$.

Prace indywidualne trzeba więc będzie traktować raczej jako rozdziały, akapity, a nawet pojedyncze wersy wielkiej księgi, którą pewnego dnia będziemy mogli nazwać Nauką o Społeczeństwie. Bibliografia [...] jest tylko spisem treści tej księgi [...]. Podstawowym narzędziem informacyjnym stała się karta dokumentacyjna, zawierająca - poza typowym opisem bibliograficznym tzw. analizę dokumentacyjną [...]. Każdy, kto pragnie przyczynić się do postępu ludzkości, mógłby natychmiastowo i mechanicznie znaleźć najbardziej szczegółową i kompletną informację $e^{43}$.

${ }^{39}$ Por. International organization and dissemination of knowledge. Selected essays of Paul Otlet, przeł., red., wstęp W. Boyd Rayward, Amsterdam 1990, s. 17-18.

40 Por. S. Vrtel-Wierczyński, Teoria bibliografii w zarysie, Wrocław 1951, s. 126, 191.

${ }^{41}$ Por. M. Dembowska, Dokumentacja i informacja naukowa. Zarys problematyki i kierunku rozwoju, Warszawa 1965, s. 54. Można więc przyjąć, że Otlet utorował drogę bibliologii rozpatrywanej jako nauka o komunikacji piśmiennej. Por. K. Migoń, Bibliologia - nauka..., s. 53.

42 Por. B. Sosińska-Kalata, Dziedzictwo Paula Otleta..., s. 100-102.

${ }^{43}$ A. Augustyniak, Dokumentacja naukowa..., s. 46-48. Cytaty są tłumaczeniami fragmentów książki W. Boyda Raywarda: The universe of information: the work of Paul 
Otlet wskazywał również, że do tego światowego archiwum ludzkiej wiedzy dostęp powinien być zapewniony z domu, za pośrednictwem dostępnej w danym czasie technologii. W swoich pracach zawarł też wizualizacje, na których przedstawił, jak jego zdaniem powinna wyglądać komunikacja człowieka z bazą magazynującą wiedzę. Proponował połączenie ze sobą różnych urządzeń, tj. odpowiedniego ekranu z telefonem, gramofonem, oraz wykorzystanie różnych mediów, tj. filmu, radia, telewizji. W swojej wizji miasta wiedzy generalnie postulował stosowanie materiałów audiowizualnych. Rozmaite formy komunikacji miały być ze sobą zintegrowane. Tym samym przewidział hipertekstowe, interaktywne i hipermedialne środowisko WWW ${ }^{44}$. Koncepcja Otleta „przywodzi na myśl ideę współczesnych systemów multimedialnych o strukturze hipertekstowej" ${ }^{45}$. Brakowało jednak odpowiednich urządzeń (komputerów) do realizacji wszystkich zamierzeń, a także nie było odpowiedniej współpracy na arenie międzynarodowej ${ }^{46}$. Z tych powodów projekt nie został zrealizowany.

Historycy nauki o informacji, np. Wouter van Acker, zwracają uwagę na to, że Otlet w kontekście organizacji i zarządzania wiedzą opowiadał się raczej za modelem drzewa, a nie za modelem sieci ${ }^{47}$. Model drzewa reprezentował stworzony w 1991 roku protokół internetowy Gopher, czyli protokół klient-serwer zaprojektowany w celu rozpowszechniania, wyszukiwania i pobierania informacji przez internet. Gopher był bardziej przyjazny dla użytkownika niż działające już wtedy protokoły telnet oraz FTP $^{48}$. Bennett Falk tak wyjaśnia zasadę działania protokołu Gopher:

jeżeli korzystasz z aplikacji sterowanej menu (takiej jak na przykład Gopher) w celu znalezienia informacji, to masz jakby przewodnika prowadzącego Cię za rękę przez skomplikowany labirynt Internetu. Na każdym etapie menu wyraźnie pokazuje Ci, gdzie jesteś i co możesz dalej zrobić. Wielu osobom metafora „drzewa” pozwala jasno zrozumieć systemy bazujące na menu. Rozpoczynasz

Otlet for documentation and informational organization, Moscow 1975. Cała wiedza miała być zgromadzona w Palais Mondial (później nazywanym Mundaneum). Por. A. Augustyniak, Dokumentacja naukowa..., s. 57.

44 Por. S. Sonvilla-Weiss, op.cit., s. 20-25.

${ }^{45}$ B. Sosińska-Kalata, Dziedzictwo Paula Otleta..., s. 105.

46 Por. ibidem, s. 90.

47 Por. W. van Acker, Seeing the network for the trees of knowledge: Paul Otlet's (1868-1944) Universal Network of Documentation, w: Networks of design: proceedings of the 2008 Annual International Conference of the Design History Society (UK), red. J. Glynne, F. Hackney, V. Minton, Boca Raton 2009, s. 402.

${ }^{48}$ Por. P. Loshin, TCP/IP clearly explained, wyd. 4, San Francisco 2003, s. 312. 
poszukiwanie od korzenia drzewa i poruszasz się po kolejnych rozwidlających się gałęziach, aż dotrzesz do liścia, który zawiera interesujące Cię dane. Jeżeli dane te są niekompletne albo też potrzebujesz dodatkowych danych, wracasz do korzenia i szukasz raz jeszcze w kolejnych menu odpowiedzi na nowe pytania. W konwencjonalnym systemie menu każde poszukiwanie prowadzi do jakiegoś liścia, gdyż plik, do którego dotarłeś, nie prowadzi już do innych użytecznych zasobów ${ }^{49}$.

Niedługo po wdrożeniu Gophera zaczęto promować nowy sposób organizowania informacji, tj. w miejsce "drzewa” zaproponowano "pajęczynę", która była gwarancją większej swobody nawigacyjnej. Pajęczyna zapewniała brak tzw. martwych uliczek, bowiem pliki i dokumenty mogły być bogate w odnośniki prowadzące do innych zasobów ${ }^{50}$. Gopher był poprzednikiem systemu WWW, który pierwszy urzeczywistnił wizję pajęczyny. Od tego momentu, jak się zdaje, odchodzi się od dominującego sposobu porządkowania informacji cyfrowych w postaci drzewa, tj. uporządkowanej, rozgałęzionej struktury hierarchicznej, i przechodzi do wprowadzonego wraz z WWW, przyjętego entuzjastycznie innego rodzaju porządkowania informacji i treści cyfrowych. WWW określa się jednocześnie jako „pajęczynę" i „labirynt” 51 . Metafora pajęczyny wskazuje, że ma się do czynienia ze strukturą przypominającą kształtem sieć pajęczą. W pajęczynie określone punkty połączone są ze sobą za pomocą nici. Twórcy metafory uznali zapewne, że podobnie w środowisku WWW pewne obiekty (węzły) połączone są za pomocą hiperłączy. W rezultacie, choć nie sposób tego zaobserwować, surfując po zasobach WWW, powstaje swoista pajęczyna obiektów oraz ich wzajemnych połączeń. Pajęczyna gwarantuje także swobodne „poruszanie się" w dowolnym kierunku, nie ma bowiem budowy rozgałęziającej się. Jeszcze dobitniej „poruszanie się" ujmuje metafora labiryntu. Nie zawsze daje się dotrzeć do tego, czego się szuka. Stąd zapewne stwierdzenie, iż WWW jest jak labirynt. Zarówno metafora pajęczyny, jak i metafora labiryntu nawiązują wprost do modelu sieci.

Na modelu drzewa bazuje KDD ${ }^{52}$, w którym, o czym wspomniałem, Otlet dostrzegał niedostatki i dlatego rozpoczął projekt stworzenia UKD. Stąd nie do końca zasadne wydaje się twierdzenie, że cała jego koncepcja opierała się na organizacyjnym modelu drzewa.

\footnotetext{
${ }^{49}$ B. Falk, Internet, Gliwice 1995, s. 177.

${ }^{50}$ Por. ibidem, s. 177.

${ }^{51}$ Por. U. Eco, Szaleństwo katalogowania, przeł. T. Kwiecień, Poznań 2009, s. 360.

52 Por. W. van Acker, op.cit., s. 399.
} 


\section{Zakończenie}

Celem artykułu była próba odpowiedzi na pytania, czy projekty Otleta są zbieżne pod pewnymi względami z WWW oraz czy tworząc Web, wzorowano się na jego pracach.

Odpowiadając na pierwsze pytanie, należy stwierdzić, że w pomysłach Otleta można odnaleźć zalążki idei hipertekstu, multimedialności oraz interaktywności, co pozwala na postawienie znaku równości między jego koncepcją a funkcjonującym dziś hipertekstowym systemem World Wide $W_{e b}^{53}$, choć nie wszyscy się z tym zgadzają.

Według Barbary Sosińskiej-Kalaty światowa, uniwersalna sieć dokumentacyjna Otleta nie całkiem słusznie jest porównywana do World Wide $W^{5}{ }^{54}$. Przyczyna może tkwić w założeniach obydwu projektów. Idea Otleta jest konceptualizacją uniwersalnego repozytorium wiedzy (ang. universal knowledge repositorium) ${ }^{55}$, podczas gdy WWW jest uniwersalnym medium służącym wymianie informacji (ang. universal medium for sharing information $)^{56}$. Zasadniczą różnicą między obydwoma projektami jest więc podejście ich twórców do zawartości gromadzonych i udostępnianych danych. Web został pomyślany tak, aby umożliwić wymienianie się wszelkimi informacjami, natomiast celem przedsięwzięcia Otleta było dostarczanie zatomizowanej, wyselekcjonowanej i wartościowej wiedzy.

Pojawiająca się w pracach Otleta idea (metafora) sieci (ang. network) była używana w sensie "sieci transportu" (na wzór sieci kolejowej). Otlet stosował to pojęcie do opisu infrastruktury komunikacyjnej pomiędzy

${ }^{53}$ Por. I. Rieusset-Lemarié, P. Otlet's Mundaneum and the international perspective in the history of documentation and information science, w: Historical studies in information science, red. T.B. Hahn, M. Buckland, Medford 1998, s. 41; A. Wright, The Web time... Wizualizacje stworzone przez Otleta pozwalają badaczom dostrzec jeszcze jedną paralelę, tym razem z semantycznym Webem. Na schematach (wykresach) przybliżających obydwa projekty ukazane są rozmaite relacje wiążące w przestrzeni i czasie obiekty i zasoby informacyjne oraz ludzi. Por. Ch. van den Heuvel, Building society, constructing knowledge, weaving the Web: Otlet's visualizations of a global information society and his concept of a universal civilization, w: European modernism and the information society: informing the present, understanding the past, red. W. Boyd Rayward, Aldershot 2008, s. 145-150.

${ }^{54}$ Por. B. Sosińska-Kalata, Dziedzictwo Paula Otleta..., s. 101.

55 Por. J.F. Rouet, The skills of document use: from text comprehension to Web-based learning, Mahwah 2006, s. 124.

${ }^{56} \mathrm{~T}$. Berners-Lee, Weaving the Web: the original design and ultimate destiny of the World Wide Web, New York 2000, s. 84. 
centrami dokumentacyjnymi a bibliotekami. Nie może więc ono być rozpatrywane jako strukturalny model bliski sieci internetowej ${ }^{57}$.

Warto jeszcze zwrócić uwagę na fakt, że we współczesnych hipertekstowych systemach informacyjno-wyszukiwawczych użytkownik i jego potrzeby informacyjne znajdują się $\mathrm{w}$ centrum systemu. Upraszczając, można przyjąć, że wokół odbiorcy projektuje się system. Otlet natomiast przejawiał niewielkie zainteresowanie użytkownikiem (także dokumentem, tekstem, autorem), za cel bowiem stawiał sobie rozwiązanie społecznego problemu, jakim było stworzenie skutecznych metod gromadzenia, przechowywania, zarządzania i udostępniania wszystkich informacji (utrwalonych na różnych nośnikach), które są lub będą potrzebne w społeczeństwie. W centrum jego projektu znalazła się więc zobiektywizowana publiczna wiedza, która ukryta była w dokumentach. W swoim systemie ",hipertekstowym” odrzucał autonomię dokumentu. Jego zdaniem ważne były tylko fakty, które za pomocą ściśle ustalonych metod można wydobyć z dokumentów. W ten sposób cała ludzka wiedza (w postaci wyselekcjonowanych faktów) byłaby zgromadzona w jednym, wielkim korpusie informacji obsługiwanym mechanicznie (za pomocą dostępnych wówczas technologii) ${ }^{58}$.

Otlet w odróżnieniu od twórców współczesnych systemów informacyjno-wyszukiwawczych abstrahował od pojęcia użytkownika i jego potrzeb. W rezultacie porównanie koncepcji Otleta do systemów hipertekstowych w ujęciu Jaya Davida Boltera, Richarda Lanhmana czy George'a P. Landowa wykazuje ogromne różnice właśnie ze względu na rolę użytkownika. Swobodne błądzenie odbiorcy pomiędzy różnymi węzłami, marginalizowanie roli autora na rzecz czytelnika-współtwórcy, brak jednej konkretnej drogi do celu poszukiwań nie pokrywa się z wyobrażeniami Otleta. Natomiast niewątpliwie wspólnym mianownikiem dla tych różnych koncepcji jest chęć stworzenia struktury wzajemnie powiązanych tekstów, odpowiadających prawdziwym relacjom pomiędzy ideami oraz pokrywających się ze sposobami funkcjonowania umysłu człowieka ${ }^{59}$.

Wizja Otleta zakładała stworzenie struktury hierarchicznej i scentralizowanej, natomiast system Tima Bernersa-Lee jest niehierarchiczny oraz zdecentralizowany ${ }^{60}$. W. Boyd Rayward w podsumowaniu artykułu,

57 Por. W. van Acker, op.cit., s. 402.

${ }^{58}$ Por. W. Boyd Rayward, Visions of Xanadu..., s. 246-248.

${ }^{59}$ M. Góralska, op.cit., s. 48-49. Por. także D.P. Wallace, Knowledge management: historical and cross-disciplinary themes, Westport 2007, s. 155.

${ }^{60}$ Por. Ch. van den Heuvel, Architecture of global knowledge: the Mundaneum and the World Wide Web, „Destination Library” 2008, nr 15, s. 52. 
w którym wykazywał podobieństwo pomysłów Otleta do współczesnego systemu hipertekstowego, wyjaśnił, że to, co Otlet opisywał przez 40 lat, było pod pewnymi względami podobne do współcześnie rozumianego hipertekstu, mimo iż żył on i pracował w erze, w której nie było jeszcze takich technologii informacyjnych jak komputery i oprogramowanie $^{61}$. Wizja Otleta, tj. „wizja globalnej sieci pojęciami niepodobnymi do dzisiejszych opisuje nic innego jak World Wide Web z mechanizmami hipertekstu" ${ }^{\prime 2}$.

Odpowiadając na drugie pytanie, można przywołać głos Morgana Alana Holta, który zwrócił uwagę na to, że pomysły Otleta (w kontekście rozwoju systemów hipertekstowych, np. WWW) były w ogóle pomijane, zapomniano bowiem o nich (nie były $w$ momencie tworzenia tych systemów szerzej znane). Choć Otlet pisał o funkcjonalnościach systemu hipertekstowego zbieżnych pod pewnymi względami z dziś funkcjonującym Webem, to jednak nie można w tym przypadku mówić o tym, aby przy tworzeniu projektu hipertekstu na potrzeby WWW "skorzystano" z koncepcji Otleta ${ }^{63}$. Ostatecznie można więc przyjąć, iż Otlet konceptualizował strukturę bliską strukturze hipertekstu, choć jego projekt nie został ani wdrożony, ani rozwinięty.

\author{
SEBASTIAN D. KOTUŁA
}

\title{
The influence of Paul Otlet upon the World Wide Web
}

Aвstract. Paul Otlet's visualizations of data integration seem to have some distinct parallels with the hypertext used in the World Wide Web. Researchers representing different disciplines (e.g., media specialists, sociologists, IT specialists and librarians)

${ }^{61}$ Por. W. Boyd Rayward, Visions of Xanadu..., s. 246-248.

${ }^{62}$ H. Zarębska, op.cit., s. 92. Por. także: Ch. van den Heuvel, Web 2.0 and the semantic web in research from a historical perspective: the designs of Paul Otlet (1868-1944) for telecommunication and machine readable documentation to organize research and society, "Knowledge Organization" 2009, t. 36, nr 4, s. 214-226.

${ }^{63}$ Por. M.A. Holt, A brief history of hypertext [online], [dostęp: 3.11.2001], dostępny $\mathrm{w}$ internecie: http://students.washington.edu/ canth/hypertext.html. Por. także H. Zarębska, op.cit., s. 91. 
all indicate essential similarities between the attempts at the information and search system conceived by the Belgian author and visionary and that of the WWW. Accordingly, the article aims at finding an answer to the question whether Otlet's visualizations are convergent to a certain degree with the WWW and whether the authors of the Web modeled their work on the Otlet's achievements?

Key words: World Wide Web, Paul Otlet. 
